\title{
Coping and Health Promotion in Persons with Dementia
}

\author{
Anne-S. Helvik
}

\section{Abstract}

For those who receive the diagnosis of dementia, their daily life is turned upside down. Dementia represents daily challenges in many aspects, cognitively, socially, emotionally and functionally. Most commonly, the dementia disorder is progressive, and currently there is no cure or treatment to stop it. Emphasizing coping and health-promotion among individuals having dementia is fundamental to obtain wellbeing as well as finding meaning-in-life. This chapter focuses on coping strategies among persons with dementia, how these are related to health-promotion, wellbeing and meaning-in-life and how nurses and health professionals can promote health and wellbeing in persons with dementia.

\section{Keywords}

Activity $\cdot$ Balancing life $\cdot$ Close family Cognitive resources $\cdot$ Cognitive impairment . Dementia disorder - Dementia friendly environment $\cdot$ Next of kin · Participation · Sense of humour

\section{A.-S. Helvik $(\bowtie)$}

Department of Public Health and Nursing, NTNU Norwegian University of Science and Technology, Trondheim, Norway

Norwegian National Advisory Unit on Ageing and Health, Vestfold Hospital Trust, Tønsberg, Norway e-mail: anne-sofie.helvik@ntnu.no

\subsection{Introduction}

Dementia is caused by various brain disorders, among which Alzheimer's disease is the most frequent $[1,2]$. Dementia is common in aged populations ( $\geq 65$ years) [3-5], but does also occur before the age of 65 years (early onset dementia) [2]. The prevalence of dementia globally, is reported to 46.8 million $[1,6]$. Furthermore, due to the aging population worldwide, the number of people living with dementia is estimated to nearly double every 20 years $[7,8]$. In most cases, dementia is progressive and characterized by cognitive impairment, changes in behaviour and/or social function and impaired activities of daily living (ADL) [9].

During progression of the functional declines, need for help from others are necessary [10]. In order to promote meaning-in-life, wellbeing and health, professional health care is essential. In the early phase, there may be a need of information and support to maintain activities of daily living, social relationships, as well as to support the individual's coping with their situation. With further functional decline, informal carers and/or formal care providers naturally must extend the scope of care and support. The health-promoting actions will aim towards compensating for loss of functioning and facilitating for change to maintain meaningful aspects in life. In the late, severe stage of dementia, the person will be fully dependent on others and will eventually die [11, 
12]. Independent of phase of dementia development, treatment and care must be provided in accordance to people with dementia's own needs and fundamental human rights and resources. In all phases of the disorder, knowledge about how people with dementia experience and cope with their current and future life situation is important for health professionals to contribute to wellbeing and meaning-in-life. There must be a shift from solely focusing on the symptoms, disabilities and restrictions related to dementia, towards capabilities and potential of persons having dementia. Despite having dementia, the individuals have resources which are fundamental to their wellbeing and health. A health-promoting perspective and approach to care is crucial and essential to fulfil these requirements.

Health-promotion utilizes a biographical approach; viewing the individual as a whole person, embedded in his or her gender, culture, identity and society [13]. Moreover, health-promotion theory focuses on resources and capabilities in and around the person. How you cope with life stressors and challenges is affected by the available internal and external resources. Personal coping resources may facilitate and contribute to resist stress and promote health [14]. In the salutogenic health model, these personal coping characteristics are termed general resistant resources (GRR) and sense of coherence (SOC) [14]. SOC is a general expression of an individual's ability to comprehend the whole situation and the capacity to use the resources available to move in a healthpromoting direction [15]. SOC reflects the extent to which a person finds life to be meaningful (a motivational and emotional disposition), manageable (readiness to control and influence) and comprehensible (a cognitive disposition) $[14,15]$. The way people are able to perceive structures, create coherence and manage change in a meaningful manner has a central impact on health [16].

\subsection{Methods}

This chapter builds on a previously published systematic meta-synthesis of studies on coping among persons with dementia [17]. This meta- synthesis was based on international published qualitative studies referring to the person with dementia's own experiences regarding coping. In total, 74 articles were found by use of a systematic and computerized search of qualitative internationally published articles between 2004 and 2019 in AgeLine, CHINDAL Complete, Embase, Medline and PsycINFO motors. The 74 articles were included based on a quality assessment by means of the CASP criteria; studies evaluated to moderate and high quality were included. The search terms are reported in the meta-synthesis [17].

\subsection{Coping with Life When Having Dementia}

Coping is how people face and handle challenging experiences and situations. In healthpromoting theory, coping is interconnected with salutogenic processes and wellbeing [18]. Successful coping is health-promoting and may contribute to an experience of hope, meaning-inlife and a sense of coherence $[14,18]$. Knowledge about how persons with dementia cope with their challenges due to their diagnosis and life changes will assist nurses, other health professionals and informal care takers to support and empower the person with dementia as well as to create healthpromoting surroundings.

Only two qualitative studies have explicitly aimed to explore coping strategies in persons with dementia $[19,20]$. However, several qualitative studies aiming to explore other phenomena than coping describe coping actions persons living with dementia use as well as how coping actions and strategies affect their life. This chapter focuses on vital coping strategies in the face of challenges and stress related to living with dementia [17]. Dementia may affect individuals differently; the progress of the disease as well as coping resources available will vary among the individuals. Thus, the coping strategies and actions used will also vary considerably in persons having dementia. Coping strategies are defined as cognitive and behavioural efforts to master, reduce or tolerate internal or external demands created 
by challenges and stress [21]. The choice of coping strategies is affected by the person's experience of internal and external resources [22]. In general, people use problem-focused strategies (strategies aiming to alter stressful situations) and emotional-focused strategies (strategies aiming to regulate emotional stress associated with the situation) and alternate between these, but in severe situations all available strategies are trigged in a global response [22].

The qualitative meta-synthesis on coping among persons with dementia [17] found several coping strategies which were grouped into four overall categories: (1) The first category of coping strategies was related to keep going and holding on to life as usual, (2) the second category was related to adapting and adjusting to the demands resulted from the disease, while (3) the third category were related to accepting the situation, followed by the (4) fourth category which was to avoid difficult situations.

\subsubsection{Coping Strategies: Keep Going and Holding on to Life as Usual}

This category of coping strategies among persons with dementia aims to keep going and holding on to activities, roles and relationships as usual [17]. This strategy seems most often to be used in early phases of dementia before the progression of the disease reduces the individual's abilities severly. This category of coping strategies included actions which contribute to (a) preserving the person s' identity, (b) normalization of the situation and (c) participating in the society.

\subsubsection{Preserving Identity}

The first set of coping actions supporting the individuals with dementia to keep going aims to preserve their identity. It refers to holding on to the identity that defines them as a person [17]. For example, they remind themselves and others by telling stories from their past life [23, 24]; this includes recalling known characteristics and strengths of one's personality [23, 25], past achievements [26], experiences from pre- vious occupations [27] and happy memories in general [28], as well as referring to difficult times they have mastered before [29]. Drawing on past roles and status contributes to preserve identity and self-esteem. By holding on to past aspects of themselves, individuals having dementia maintain their sense of self [17]. Past roles and achievements remind them of who they are, despite their new strange situation.

In a health-promoting perspective, preserving identity and self-esteem helps to find meaning-in-life and keep going. Perceived meaning-in-life and self-esteem are important to handle challenges and thereby reduce stress; finding meaning-in-life in the midst of dementia may contribute to a renewed understanding of themselves. Thus, preserving identity is healthpromoting. Knowledge about such identitypreserving actions and their health-promoting potential is fundamental for the nursing professionals using the nurse-patient interaction as a resource for preserving and strengthening these individuals' identity and self-esteem. As severity of dementia increases, talking about or recalling one's personal characteristics, past roles, previous hobbies, activities and past achievements may prove difficult. Consequently, the health professionals when caring for persons with dementia should initiate and utilize communication contributing to preserving identity and wellbeing. Pictures from previous times and written histories can be used to facilitate for such communication, which is termed "healthpromoting nurse-patient interaction" (see [30], Chap. 10 in this book). It is therefore important that health personnell ask for such material and for the life story in an early phase of dementia. In cases where dementia has progressed, next of kin and close family members may contribute with such information. Such identity supporting communication could for example take place during regular care interaction.

\subsubsection{Maintaining Normality}

The second set of coping actions to keep going is maintaining normality. The person with dementia seeks to reduce his/her worries due to the diagnosis [17]. The above-mentioned meta- 
synthesis [17] revealed that they maintained normality by keeping up with activities, roles and relationships they had before. They normalize the new situation by trying to go on as usual [31]. Individuals having dementia made extra efforts to appear in accordance with the social norms and thus avoid negative reactions and problems [32]. These coping actions preserving their previous way of living released will-power and hope for a good life in the future [33]. Moreover, memory loss was explained by high age rather than dementia, which facilitated normalization and thereby an experience of maintaining normality, decreased worries and increased wellbeing [34, 35]. Additionally, normality was maintained by using high age and loss of interest rather than dementia to explain giving up one's occupation or common activities [27] and keep going focusing on aspects of one's life which are still manageable. By keep telling oneself that the dementia and experiences related to it were of minor importance for their overall situation [23], they could keep going 'as usual'. Also, comparing themselves with others having poorer health conditions made them feel that what they lived through was not that special [35].

Normalization may be a way the person with dementia use to experience control. Normalization strategies facilitate manageability as well as comprehensibility (both SOC) and thereby wellbeing and health. It is normal to stop with activities when these are no longer of any interest. So, when you as a nurse or health professional experience that persons with dementia explain lack of interest or use age as reasons for stopping with previous interesting activities, it may be an attempt to normalize the situation. However, it may also be a natural change. Even so, it may be that the specific activity is stressful by representing challenges which they are not able to handle anymore because of their dementia. Thus, health professionals should be supportive and understand such attempts to normalize their situation, actions and priorities. Health professionals may ask if tailored ways to participate in activities etc. are of interest; that is to check if any support such as going together with them, support driving, or provide what is needed could make the activity manageable. In other words, if someone in the society such as a volunteer or significant other could arrange or contribute, a person with dementia could find the activities still manageable and pleasant. This means that individuals with dementia may still be able to perform the activities which they like, but these activities do now include specific challenges calling for assistance. Therefore, health professionals' role could be to inform next of kin and relevant others about recent change in interest and its reasons, and eventually their possibility to facilitate for participating in activities, etc.

Coping actions directing normalization intend to maintain activities which the individuals are used to, since such continuation gives meaning and wellbeing as well as hope for the future. Meaningfulness, identifying solutions and having resources to solve challenges are essential to sense of coherence (SOC) [14, 15], which is central for health-promoting processes contributing to wellbeing. Moreover, prevailing normality may represent a general resistance resource (GRR); when the person with dementia experience to cope with challenges, this contributes to satisfaction, self-confidence and joy [36], all of which are important health-promotion processes [16]. The role of the health professionals' is to explain the positive gains by normalization to family members and others, and eventually to facilitate for participating in activities for an extended period of time.

\subsubsection{Contribute to the Society}

The third set of coping actions that persons with dementia use to keep going and holding on to life as before is aiming to contribute to the society in the way they can. It refers to the value of still being able to do meaningful activities and being useful [17]. However, their way of contributing to others may differ from before. Individuals having dementia search for new ways to be useful [24] and ways to use their remaining abilities to contribute in a larger context. They search for ways to contribute in the family and household [37], to be useful for others [38], doing something practical to help another person [27] and engage in 
voluntary work to the best for the society [27, $38,39]$. The influence of utilizing such coping strategies include a feeling of being someone to others and to oneself [27] and having purpose in life [39]. Thus, despite having dementia, being someone who contributes to the society provides a sense of meaning-in-life as well as coherence between the person with dementia, his/her surroundings and the society.

Accordingly, nurses and health professionals' health-promotion initiatives among people with dementia, especially in the early phase, should ensure that these individuals can support, contribute and feel valuable to their family, friends as well as to the society. However, such health-promotion initiatives must be based on knowledge about the individual as a person and what he/she wants. Suggestions and activities should be built upon his/her previous experiences and knowledge as well as interests and available resources. Such support can be implemented in an out-patient clinic consultation and in a home visit when planning future actions for retaining health and promoting wellbeing. Counselling of the person with dementia, the next of kin and other informal care givers should preferably incorporate information about that contributing to others and the society may represent a vital salutary resource for wellbeing. Dementia friendly families, neighbourhoods and societies represent environments where persons with dementia can contribute in the society and maintain normality. As a result, they are enabled and empowered to keep on going, holding on to activities, roles and relationships 'as usual' for an extended period, which provides wellbeing and quality of life. Furthermore, health-promoting initiatives and dementia friendly environments may facilitate for adaption and adjustment to the situation and demands.

\subsubsection{Coping Strategies: Adapting and Adjusting to the Demands}

Adapting and adjusting to the demands is the second category of coping strategies that was found in the meta-synthesis [17]. These strate- gies describe how people adapt and adjust their own expectations toward themselves and activities which they can perform. The different coping actions involve being active, planning and making changes to handle the situation. This category of coping strategies includes actions aiming at (a) Taking control and compensate and (b) Reframing the identity.

\subsubsection{Taking Control and Compensate}

This first set of coping actions, taking control and compensate, includes what persons with dementia do to continue being active, both physically and cognitively [17]. Furthermore, coping actions directing the need of information, compensation for loss of functionality, and planning to reduce stress, are central.

Being physically and cognitively active includes doing life-long hobbies and continue with previous habits to provide enjoyment [40]. Maintaining meaningful activities were seen as helpful to cope with symptoms of dementia and contributed to an experience of control [34]. Continuing one's daily routines helped to stay in control of the situation and to preserve identity [41]. Participating in leisure activities was a part of counteracting development of disease, it helps keeping the mind active and supports a sense of meaningfulness [34]. Correspondingly, physical activity was experienced to delay deterioration [42], but also to develop social attributes and avoiding being defined only by their dementia [29]. In times of stress, relying on religion and life-values was important for a sense of control and comfort [20]. Moreover, involvement in music could give persons with dementia a sense of empowerment and control [43].

The overall coping category termed 'keep going and holding on to life' which was described firstly in this chapter, may also involve decisions to not participate in specific activities. The persons with dementia reasoned their change of participation to increased age and loss of interest rather than difficulties due to dementia [27]. This means that emotional coping strategies were used to regulate emotional stress associated with the situation rather than solving 
the problems or challenges caused by the situation. Persons continuing taking part in activities, also when experiencing challenges, strived to take control [17]. In this matter, problem-solving rather than emotional coping strategies seem sufficient; by taking control and compensate for loss of functionality the challenges could be handled. Participation in these specific activities was seen as meaningful [34]. Taking control over challenges imply both identifying solutions and having resources (either internal and/or external) to solve the challenges which represent two of three essential elements in SOC $[14,15]$. The third aspect of SOC is finding such activities meaningful $[14,15]$. A strong SOC is important for the health-promoting processes contributing to wellbeing. Thus, nurses and other health professionals should inform next of kin about the importance of persons with dementia taking control by being physically and cognitively active and facilitating for participation in such activities when indicated.

The persons with dementia adjusted to the new demands by putting extra effort into preparations and accomplishment to partake in activities [17]. They developed strategies to compensate for the impairment [44] in order to avoid mistakes due to memory loss. Utilizing such strategies and investing time and effort into planning and organizing to better meet difficulties and memory loss were part of taking control and adapting to the situation $[40,45]$. Strategies such as writing notes [44], use of external memory aids [35], use of technology to keep control [46] and asking for assistance from others [42] e.g. external services, friends and family [47] were used to compensate for memory loss, to remember routines and to provide a sense of control and meaningfulness. Also, cognitive exercise was used to improve memory [47] and some actions contributed to maintain autonomy. Holding on to autonomy could be managed by for example going to familiar places so they could handle the activity by themselves [48] or avoiding concerns of their partner and others [44].

The coping actions described here show how persons with dementia compensate for reduced cognitive functioning and handle challenges to be active. They put time and effort into planning activities, use technical tools to assist them as well as asking for help from others to compensate for loss of capacity. Trying to adapt to their new life situation caused by dementia, they described coping strategies which supported a sense of control and autonomy. The various coping actions are based in available resources, strength to stand strains (resilience) [49], a wish to overcome obstructions and finding meaning by doing so, all of which are salutogenic factors promoting wellbeing and health $[14,15]$.

As shown, individuals having dementia use available personal resources as well as resources in their social network, environment and provided by professionals when necessary. If properly met, asking for help is health-promoting. By means of counselling, empowerment as well as health-promoting interaction, nurses and other health professionals can support coping strategies which improve control, adaption and adjustment to their situation. A sense of control, adaption and adjusting represent vital resources for wellbeing and health [50].

Planning for the future, i.e. being proactive in managing dementia is a part of the adapting and adjusting coping strategies [17]. Such planning might include contacting internet support groups to get knowledge of dementia, finding ideas about how to make appropriate changes [47], to contact health care services when you know help will be needed in the future [51] or accessing groups with other people having dementia [52].

As shown above, the described coping actions aim at taking control and adapt to the situation by looking ahead to future needs. To master their situation here-and-now as well as preparing for the coming challenges, they searched for relevant knowledge and external resources. To master their situation, individuals having dementia took initiative regarding planning their finances, place of living, and their last will. Such planning contributes to wellbeing and hope for a good life also during the times of more severe dementia which they know will come. 
The evidence presented so far in this chapter highlights the importance of planning the future while necessary resources still are available. Hence, health professionals should initiate a dialogue with the person having dementia, provide information as well as practical and emotional support to promote such planning, which may include to educate the informal caregivers. Information, counselling or dialogue in support groups as well as the utilization of future planning may prepare for changes, contribute to adaption, adjustment, wellbeing and health. The timing of such information, counselling or dialogue is essential. The person having dementia needs to be mentally ready or prepared to focus on the future, representing a vulnerable state. Thus, health-promoting nurse-patient interaction including acknowledgement, respect, emotional support and sensitivity for the individual's situation, experiences and feelings is an important resource supporting coping and wellbeing [30]. Health-promoting nurse-patient interaction is also an important tool for identifying when the person having dementia and his/her family are ready to focus on planning for the future.

\subsubsection{Reframing Identity}

The second set of coping actions refers to reframing the identity [17]. It includes how a person encourages identity by thinking differently about oneself [37]. By comparing themselves with those who were worse off, persons with dementia affirm their own identity and self-worth [24, 29, 37]. Reframing one's identity contributes to hope and satisfaction in life [53]. Reframing the identity can also include decision-making, for instance decisions of whether to ask for help or not [25, 37]. A decision of informing others about one's disease is seen as a key element in the process of coming to terms with the diagnosis of dementia and constructing a new sense of self [54].

Preserving, affirming and reframing identity are different coping actions to cope with changed health resources. Reframing actions help to adapt to the diminished resources caused by the dementia. Both preserving and reframing actions are emotional-focused coping strategies contributing to wellbeing. Adaption to change and reframing strategies are linked to resilience and selftranscendence [50, 55]. Self-transcendence (see Chap. 9 in this book) holds adaption to changes in life as one of the key resources for wellbeing in vulnerable populations [50]. Adaption to changes is an integral process involved in the intra-personal aspect of self-transcendence [56]. Participation in groups of peers arranged by daycare centres or other resource groups may support identity reframing. Nurses or other health professionals should provide information about such groups available.

How people with dementia adapt and adjust their expectations toward themselves and their capacities, represent one of four overall strategies of coping among persons with dementia. The next coping category is termed accepting the situation, which is also a key aspect of intra-personal self-transcendence (see Chap. 9).

\subsubsection{Coping Strategies: Accepting the Situation}

Accepting one's situation includes acknowledgement and acceptance of the changed situation characterized by the dementia diagnosis and loss of memory. The accepting coping strategies are based in understanding of their capabilities; that is, what they can perform independently and when they need assistance from others [17].

\subsubsection{Position in Life}

This set of coping strategies includes actions to have a position in life [17]. When the individuals having dementia accept their changed situation, they simultaneously deny dementia to rule one's life [57]. The focus is shifting from seeing dementia as a disease towards living well with the resources they still possess [58]. Thus, they highlight the possibilities which they still have in life [28, 59-61], maintaining a positive view of oneself [59] and appreciating the present moment [34]. These positive approaches add both hope for a good life in the future and meaning-in-life regardless of the future prospect $[34,60,62]$. 
When the persons with dementia are accepting the changes and refind a position in life, they do not combat the consequences of their disease, but search for ways of living well with the dementia and the resources they still possess combined with asking for support from others when needed. These coping strategies support hope and meaningfulness, and thereby promote health and wellbeing among the person with dementia. Furthermore, coping actions reflecting acceptation of change are linked to self-transcendence. Self-transcendence is strengthened both by adaption to change in life (as said above) and acceptation of this change [50].

Health care professionals' knowledge about various kinds of coping actions and their possible gains is important to initiate a dialogue supporting the individuals to adapt and accept the changed life situation caused by dementia. By means of counselling, nurses and other health professionals can promote quality of life and wellbeing, independently of context and whether the counselling dialogue is with the person with dementia or those staying close to the person.

\subsubsection{Avoiding Coping Strategies}

This last coping category includes how individuals having dementia directly and indirectly avoid situations which cause stress and challenges due to the disease [17]. Hence, these strategies include direct resistance and indirect resistance (distraction) of the disease.

\subsubsection{Direct Resistance of the Disease}

The set of coping actions termed direct resistance of the disease involves actions to resist change, adaption or help from others to hinder accepting the diagnosis and its progression over time $[17,47]$. The aim of these actions is to prevent themselves from thinking about the disease, its consequences and the future life with dementia [62-64].

The resistance actions intend to avoid focusing on the realities of the dementia [65], and are used to fight stigma related to the disease and treats of identity [47]. Direct resistance actions include withdrawing from participation in different settings and concealing difficulties from others, which lead to isolation [65]. Consequently, the use of these coping strategies may actively avoid situations requiring support by others, and assistance or information from others might be escaped [66]. Furthermore, to avoid focusing on the realities of dementia they elude situations where they may meet others with dementia or those with a further progression of dementia than themselves [38]. Moreover, linguistic strategies aiming for emotionally distancing themselves from the disease are also seen as part of such avoiding coping strategies [65].

\subsubsection{Distracting from the Disease}

The distracting from the disease-actions aims to distract themselves from dementia and its consequences [17]. Thus, they distract themselves from being confronted with symptoms and changes due to reduced cognitive abilities.

Distracting coping actions are understood as indirect avoiding strategies. Such actions may be to keep busy, active and fully occupied to escape the realities of dementia $[67,68]$. For example, being actively partaking in social settings may be a way to get distance between themselves and dementia [20].

However, these coping actions aiming for resistance and distracting may give a short relief from the stress, challenges and difficulties caused by the disease. Thus, these strategies are mainly utilized to reduce overwhelming stress and challenges. The dementia itself and thoughts of the potential consequences of dementia put tremendous demands on a person. People with dementia may experience that available resources in themselves or in their context are limited. Accordingly, both resistance and distraction strategies may be a natural as well as a rational reaction in the context of a crisis. However, their challenges will not be solved or disappear by these strategies; therefore, over time such strategies will not be health-promoting.

Health-promoting approaches applied by nurses and other health professional should include emotional support and guidance. Despite 
the person with dementia may resist the changes, emotional support can help to release some pressure, strain and stress and thereby release health resources. Furthermore, over time emotional support may support adaption and acceptation of their situation, which is key to wellbeing and health. By means of counselling, health professionals should provide the family with knowledge about normal reactions to crises and possible important factors for health and wellbeing. Such knowledge is important to empower the person with dementia as well as his/her family. Such counselling must be based on the readiness of the person having dementia. Thus, the content and method will depend on the situation and the actual persons involved. Empowerment is an important resource to strengthen coping and wellbeing [69].

\subsection{A Life with Dementia - An Art of Balance}

Persons with dementia are seen to utilize four overall categories of coping strategies [17]. The use of these coping strategies is not based in a chronological order or a linear process starting with avoidance and ending in acceptance of the situation. These strategies should rather be seen as potential ways to meet stress and challenges following dementia [17]; that is, balancing the life with dementia. As previously mentioned, the strategies chosen will depend on the appraisals of the challenges as well as the available resources. Therefore, one person may respond differently to a challenge than another in the same situation, as well as showing a different reaction the next time he or she encounter approximately the same challenge. One alternates between the available strategies depending of what is deemed the best solution in the specific context. Furthermore, in severe situations, a global coping response is triggered including use of all available strategies simultaneously to handle the challenge [22].

Persons with dementia use coping strategies to balance life with dementia independently of limitations in health resources. Coping strategies handling stress and challenges enhance hope and meaning-in-life [17].
How you respond to challenges is, as previously appointed, not only dependent on the challenges but also on the available resources. These are resources within the person self, within close family and next of kin as well as in the environment outside the family.

Firstly, a person's inner strength to handle strain and challenges, i.e. the persons resilience [49], may differ, but is essential for coping and health [70]. Resilience includes abilities to regain inner strength and coping resources while facing different kinds of hardship [70]. A sense of humour is another positive personal quality for coping pointed out by persons with dementia [17]. A sense of humour represents the ability to see the humorous aspects of a situation which reduces stress and elicits positive emotions [17].

Secondly, close family and close social relations are vital resources in peoples' lives, especially in phases of vulnerability. Therefore, such relationships are crucial resources for individuals having dementia in the face of stress. Having vital social relations affects how he or she appraises the stressors and the challenges. Next of kin and close family may give emotional support, backing and practical help [17]. The family's resources may differ with personal health, socioeconomic status, but also regard to knowledge about dementia. Empowerment by means of counselling the close family, i.e. by providing knowledge about dementia and health-promotion, is essential. Empowering courses are sometimes offered online, by peers providing volunteer groups for close family or coping courses arranged by the local health care service or by health agencies. Support from family has also been linked not only to coping, but also directly to meaning-inlife [71] among persons with dementia.

Lastly, coping strategies to reduce and alter stress and challenges are affected by environmental factors. For example, staying in a dementia friendly neighbourhood and society may support coping strategies promoting balance in life, wellbeing and health. The World Health Organization's 'age-friendly' policy movement [1] and dementia awareness campaign [72], underline the importance of supporting environments which facilitate empowerment of persons 
with dementia and thereby making it possible for them to take part in the society. There must be a shift in the perspective of dementia from only focusing on symptoms, disabilities and restrictions towards capabilities, resources and potential of persons with dementia, not only in health care services but also in public planning. Dementia friendly environment principles involve high safety, good structure and familiarity which are meant to reduce stress and challenges and thereby promote coping and participation in the society [73-76].

\subsection{Conclusion}

This chapter focuses on coping strategies defined as cognitive and behavioural efforts to master, reduce or tolerate internal or external demands created by challenges and stress and how persons with dementia cope with challenges due to the disorder. How persons with dementia themselves express use of coping strategies has been reported in qualitative studies, and a metasynthesis of these studies found that persons with dementia used four overall categories of coping strategies: (1) The first category was related to keep going and holding on to life as usual, (2) the second category included adapting and adjusting to the demands resulting from the disease, while (3) the third category embraced accepting the situation, followed by the (4) fourth category centering on avoiding difficult situations. The present chapter describes these coping strategies, how they are linked to health-promotion, wellbeing and meaning-in-life and how persons with dementia use these coping strategies to balance their life with dementia. In treatment and care of persons with dementia, there must be a shift from primarily focusing on symptoms, disabilities and restrictions towards coping and health-promotion, including emphasize on capabilities, resources and potential of persons having dementia.

Nurses and health professionals can promote health and wellbeing in persons with dementia: in the early phase of dementia, information and support to maintain activities of daily living, coping and social relationships are needed. With further functional decline, informal carers and/ or formal care providers naturally must extend the scope of care and support. The healthpromoting actions aim to compensate for loss of functioning and to facilitate meaningfulness in life.

\section{Take Home Messages}

- There must be a shift in dementia care from only focusing on symptoms, disabilities and restrictions towards capabilities, resources and potential of persons with dementia.

- Knowledge about dementia based in an integrated understanding of pathogenesis and salutogenesis, represents a basis for highquality dementia care.

- Coping strategies such as 'keep going and holding on to life', 'adapting and adjusting to the situation and demands', and 'accepting the situation' contribute to meaningfulness and wellbeing.

- Persons with dementia chose coping strategies and actions dependent on the stressors and challenges they experience and available personal and external resources.

- Coping aims to balance one's life with dementia.

\section{References}

1. World Health Organization. World report on ageing and health. Geneva: World Health Organization; 2015.

2. Engedal K, Haugen P. Demens - sykdommer, diagnostikk og behandling. Tønsberg: Forlaget aldring og helse - akademisk; 2018; [Norwegian].

3. Ferri CP, et al. Global prevalence of dementia: a Delphi consensus study. Lancet. 2005;366(9503):2112-7.

4. Berr C, Wancata J, Ritchie K. Prevalence of dementia in the elderly in Europe. Eur Neuropsychopharmacol. 2005;15(4):463-71.

5. Shi Z, et al. Prevalence and clinical predictors of cognitive impairment in individuals aged 80 years and older in rural China. Dement Geriatr Cogn Disord. 2013;36(3-4):171-8.

6. Prince M, et al. World Alzheimer Report 2015. An analysis of prevalence, incidence, cost and trends. London: Alzheimer's Disease International; 2015. 
7. Prince $\mathrm{M}$, et al. The global prevalence of dementia: a systematic review and metaanalysis. Alzheimers Dement. 2013;9(1):63-75 e2.

8. Sosa-Ortiz AL, Acosta-Castillo I, Prince MJ. Epidemiology of dementias and Alzheimer's disease. Arch Med Res. 2012;43(8):600-8.

9. Potkin SG. The ABC of Alzheimer's disease: ADL and improving day-to-day functioning of patients. Int Psychogeriatr. 2002;14(Suppl 1):7-26.

10. van der Steen J, et al. White paper defining optimal palliative care in older people with dementia: a Delphi study and recommendations from the European Association for Palliative Care (EAPC). Palliat Med. 2014;28(3):197-209.

11. Engedal K, et al. Demens. Fakta og utfordringer : Lærebok. Tønsberg: Forlaget Aldring og helse; 2009. $424 \mathrm{~s}$.

12. World Health Organization. Dementia: a public health priority. Geneva: World Helth Organization; 2012.

13. Naidoo J, Wills J. Health studies: an introduction. Hampshire: Palgrave; 2001.

14. Antonovsky A. Unraveling the mystery of health. San Francisco: Jossey-Bass; 1987.

15. Lindstrom B, Eriksson M. Salutogenesis. J Epidemiol Community Health. 2005;59(6):440-2.

16. Eriksson M, Lindström B. A salutogenic interpretation of the Ottawa Charter. Health Promot Int. 2008;23(2):190-9.

17. Bjørkløf GH, et al. Balancing the struggle to live with dementia: a systematic meta-synthesis of coping. BMC Geriatr. 2019;19(1):295.

18. Eriksson M. The sense of coherence in the salutogenic model of health. In: Mittelmark MB, Sagy S, Eriksson M, Bauer GF, Pelikan JM, Lindström B, Espnes GA, editors. The handbook of salutogenesis. New York: Springer; 2017.

19. Sharp BK. Stress as experienced by people with dementia: an interpretative phenomenological analysis. Dementia (London). 2019;18(4):1427-45.

20. Frazer S, Oyebode J, Cleary A. How older women who live alone with dementia make sense of their experiences: an interpretative phenomenological analysis. Dementia. 2011;11(5):677-93.

21. Folkman S. Personal control and stress and coping processes: a theoretical analysis. J Pers Soc Psychol. 1984;46(4):839-52.

22. Lazarus RS, Folkman S. Stress, appraisal and coping. New York: Springer; 1984.

23. Dalby P, Sperlinger D, Boddington S. The lived experience of spirituality and dementia in older people living with mild to moderate dementia. Dementia (London). 2012;11(1):75-94.

24. Clare L, et al. The experience of living with dementia in residential care: an interpretative phenomenological analysis. Gerontologist. 2008;48(6):711-20.

25. Nowell Z, Thornton A, Simpson J. The subjective experience of personhood in dementia care settings. Dementia. 2013;12(4):394-409.
26. Hedman R, et al. How people with Alzheimer's disease express their sense of self: analysis using rom Harré's theory of selfhood. Dementia. 2013;12(6): 713-33.

27. Öhman A, Nygård L. Meanings and motives for engagement in self-chosen daily life occupations among individuals with Alzheimer's disease. OTJR. 2005;25(3):89-97.

28. Mjørud M, et al. Living with dementia in a nursing home, as described by persons with dementia: a phenomenological hermeneutic study. BMC Health Serv Res. 2017;17(1):93.

29. Tolhurst E, Weicht B. Preserving personhood. The strategies of men negotiating the experience of dementia. J Aging Stud. 2017;40:29-35.

30. Haugan G. Nurse-patient interation - a vital salutary resource in nursing home care. In Haugan G, Eriksson M. Health promotion in health care - vital theories and research. Chapter 10, Springer Scientific Publisher; 2021.

31. Bronner K, et al. Which medical and social decision topics are important after early diagnosis of Alzheimer's disease from the perspectives of people with Alzheimer's disease, spouses and professionals? BMC Res Notes. 2016;9:149.

32. Mazaheri M, et al. Experiences of living with dementia: qualitative content analysis of semi-structured interviews. J Clin Nurs. 2013;22(21-22):3032-41.

33. Rostad D, Hellzen O, Enmarker I. The meaning of being young with dementia and living at home. Nurs Rep. 2013;3(1):12-7.

34. Genoe MR, Dupuis SL. The role of leisure within the dementia context. Dementia (London). 2014;13(1):33-58.

35. Lee SM, Roen K, Thornton A. The psychological impact of a diagnosis of Alzheimer's disease. Dementia (London). 2014;13(3):289-305.

36. Johannessen A, et al. "To be, or not to be": experiencing deterioration among people with young-onset dementia living alone. Int J Qual Stud Health Wellbeing. 2018;13(1):1490620.

37. Genoe $\mathrm{M}$, et al. Honouring identity through mealtimes in families living with dementia. J Aging Stud. 2010;24(3):181-93.

38. MacRae H. Self and other: the importance of social interaction and social relationships in shaping the experience of early-stage Alzheimer's disease. J Aging Stud. 2011;25(4):445-56.

39. Tak SH, et al. Activity engagement: perspectives from nursing home residents with dementia. Educ Gerontol. 2015;41(3):182-92.

40. Gilmour JA, Huntington AD. Finding the balance: living with memory loss. Int J Nurs Pract. 2005;11(3):118-24.

41. van Zadelhoff E, et al. Good care in group home living for people with dementia. Experiences of residents, family and nursing staff. J Clin Nurs. 2011;20(17-18):2490-500. 
42. Hedman R, et al. How people with Alzheimer's disease express their sense of self: analysis using Rom Harre's theory of selfhood. Dementia (London). 2013;12(6):713-33.

43. Sixsmith A, Gibson G. Music and the wellbeing of people with dementia. Ageing Soc. 2007;1:127-45.

44. Derksen E, et al. Impact of diagnostic disclosure in dementia on patients and carers: qualitative case series analysis. Aging Ment Health. 2006;10(5): 525-31.

45. Chaplin R, Davidson I. What are the experiences of people with dementia in employment? Dementia (London). 2016;15(2):147-61.

46. Nygard L. Meaning of everyday technology as experienced by people with dementia who live alone. Dementia. 2008;7(4):481-502.

47. Genoe MR, et al. Adjusting to mealtime change within the context of dementia. Can J Aging. 2012;31(2):173-94.

48. Brorsson A, et al. Accessibility in public space as perceived by people with Alzheimer's disease. Dementia. 2011;10(4):587-602.

49. Nygren B, et al. Recillience, sence, of coherence, purpose in life and self-tracendence in relation to perceived physical and mental health among the oldest old. Aging Ment Health. 2005;9(4):354-62.

50. Nordberg A, et al. Self-transendence (ST) among very old people - its associationas to social and medical factors and development over five years. Arch Gerontol Geriatr. 2015;61(2):247-81.

51. Stephan A, et al. Barriers and facilitators to the access to and use of formal dementia care: findings of a focus group study with people with dementia, informal carers and health and social care professionals in eight European countries. BMC Geriatr. 2018;18(1):131.

52. Read S, Toye C, Wynaden D. Experiences and expectations of living with dementia: a qualitative study. Collegian. 2017;24(5):427-32.

53. Wolverson Radbourne EL, Clarke C, Moniz-Cook E. Remaining hopeful in early-stage dementia: a qualitative study. Aging Ment Health. 2010;14(4):450-60.

54. Weaks D, Wilkinson H, McLeod J. Daring to tell: the importance of telling others about a diagnosis of dementia. Ageing Soc. 2015;35(4):765-84.

55. Rutter M. Resilience in the face of adversity: protective factors and resistance to psychiatric disorder. $\mathrm{Br} \mathrm{J}$ Psychiatry. 1985;147(6):598-611.

56. Haugan G. Life satisfaction in cognitively intact longterm nursing home patients: symptoms, distress, wellbeing and nurse-patient interaction. In: Sarracino IM, editor. Beyond money-the social roots for health and wellbeing. New York: NOVA Scientific Publisher; 2014. p. 165-211.

57. Langdon SA, Eagle A, Warner J. Making sense of dementia in the social world: a qualitative study. Soc Sci Med. 2007;64(4):989-1000.

58. Hillman A, et al. Dualities of dementia illness narratives and their role in a narrative economy. Sociol Health Illn. 2018;40(5):874-91.
59. Borley G, Hardy S. A qualitative study on becoming cared for in Alzheimer's disease: the effects to women's sense of identity. Aging Ment Health. 2017;21(10):1017-22.

60. Pesonen HM, Remes AM, Isola A. Diagnosis of dementia as a turning point among Finnish families: a qualitative study. Nurs Health Sci. 2013;15(4):489-96.

61. Hulko W. From 'not a big deal' to 'hellish': experiences of older people with dementia. J Aging Stud. 2009;23(3):131-44.

62. Clemerson G, Walsh S, Isaac C. Towards living well with young onset dementia: an exploration of coping from the perspective of those diagnosed. Dementia (London). 2014;13(4):451-66.

63. de Witt L, Ploeg J, Black M. Living on the threshold: the spatial experience of living alone with dementia. Dementia. 2009;8(2):263-91.

64. de Witt L, Ploeg J, Black M. Living alone with dementia: an interpretive phenomenological study with older women. J Adv Nurs. 2010;66(8):1698-707.

65. Aldridge H, Fisher P, Laidlaw K. Experiences of shame for people with dementia: an interpretative phenomenological analysis. Dementia (London). 2019;18(5):1896-911.

66. Svanström R, Sundler AJ. Gradually losing one's foothold - a fragmented existence when living alone with dementia. Dementia (London). 2015;14(2): 145-63.

67. MacKinlay E. Using spiritual reminiscence with a small group of Latvian residents with dementia in a nursing home: a multifaith and multicultural perspective. J Relig Spiritual Aging. 2009;21(4):318-29.

68. Vernooij-Dassen $M$, et al. Receiving a diagnosis of dementia: the experience over time. Dementia. 2006;5(3):397-410.

69. Tveiten S, Knutsen I. Empowering dialoguesthe patients' perspective. Scand J Caring Sci. 2011;25:333-40.

70. Wolin S, Wolin S. The resilient self. New York: Villard Books; 1993.

71. Eriksen S, et al. The experience of relations in persons with dementia: a systematic meta-synthesis. Dement Geriatr Cogn Disord. 2016;42:342-68.

72. World Health Organization. Dementia: a public health priority. Geneva: World Health Organization; 2012.

73. Day K, Carreon D, Stump C. The therapeutic design of environments for people with dementia a review of the empirical research. Gerontologist. 2000;40(4):397-416.

74. Marquardt GP, Bueter KMA, Motzek TM. Impact of the design of the built environment on people with dementia: an evidence-based review. HERD. 2014;8(1):127-57.

75. Calkins MP. Evidence-based long term care design. NeuroRehabilitation. 2009;25(3):145-54.

76. van Hoof J, et al. Environmental interventions and the design of homes for older adults with dementia: an overview. Am J Alzheimers Dis Other Dement. 2010;25(3):202-32. 
Open Access This chapter is licensed under the terms of the Creative Commons Attribution 4.0 International License (http://creativecommons.org/licenses/by/4.0/), which permits use, sharing, adaptation, distribution and reproduction in any medium or format, as long as you give appropriate credit to the original author(s) and the source, provide a link to the Creative Commons license and indicate if changes were made.

The images or other third party material in this chapter are included in the chapter's Creative Commons license, unless indicated otherwise in a credit line to the material. If material is not included in the chapter's Creative Commons license and your intended use is not permitted by statutory regulation or exceeds the permitted use, you will need to obtain permission directly from the copyright holder.

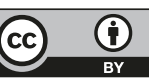

